\title{
Cartilage and Bone Metabolism in Rheumatoid Arthritis \\ Differences between Rapid and Slow Progression of Disease Identified by Serum Markers of Cartilage Metabolism
}

\author{
Bengt Månsson, ${ }^{\star \ddagger}$ Dennis Carey, ${ }^{\mathfrak{5}}$ Mauro Alini, ${ }^{\$}$ Mirela lonescu, ${ }^{\S}$ Lawrence C. Rosenberg," A. Robin Poole, $\$$ \\ Dick Heinegård, ${ }^{\ddagger}$ and Tore Saxne* \\ * Department of Rheumatology and ${ }^{\ddagger}$ Medical and Physiological Chemistry, Lund University, S-22185 Lund, Sweden; ${ }^{\S}$ Joint Diseases \\ Laboratory, Shriners Hospital for Crippled Children, Department of Surgery, McGill University, Montreal, Quebec, Canada; and \\ "Orthopaedic Research Laboratories and Montefiore Hospital and Medical Center, Bronx, New York 10467
}

\begin{abstract}
Serum concentrations of specific cartilage and bone molecules reflecting tissue turnover were measured in two well-defined patient groups with early rheumatoid arthritis with distinctly different disease outcome to see if early differences in their levels are prognostic of the rate of joint destruction. Compared with a matched normal population, increased concentrations of cartilage oligomeric matrix protein (COMP) were found in all patients who developed rapid hip joint destruction. In contrast, levels of a putative marker of cartilage aggrecan synthesis, the chondroitin sulfate epitope 846, were increased only in patients with slow joint destruction. Levels of bone sialoprotein (BSP) were increased in both groups, as were levels of the C-propeptide of type II procollagen (CPII), a marker of collagen II synthesis.

The increased concentrations of the 846 epitope in patients with slow joint destruction suggest increased aggrecan synthesis. The low levels of the 846 epitope in patients with rapid joint destruction, concomitant with elevated levels of CPII, suggest a selective increase in collagen synthesis. The elevated BSP levels indicate an increased bone turnover in both groups. Thus elevated serum levels of COMP may indicate an unfavorable prognosis for rapid joint destruction, whereas elevated 846 epitope indicates a more favorable prognosis. (J. Clin. Invest. 1995. 95:1071-1077.) Key words: cartilage $\bullet$ bone $\cdot$ rheumatoid arthritis $\bullet$ joint destruction • prognosis
\end{abstract}

\section{Introduction}

Rheumatoid arthritis (RA) is a disease characterized by destruction of joint structures such as articular cartilage and bone (1). The pathogenetic mechanisms responsible for tissue destruction are not well understood (2-4). Furthermore, it is not clear why joint destruction progresses very slowly in some patients and causes little tissue derangement, whereas in others extensive

Address correspondence to Dr. Tore Saxne, Department of Rheumatology, Lund University Hospital, S-221 85 Lund, Sweden. D. Carey's present address is Pediatric Endocrinology, Schneider Childrens Hospital, New Hyde Park, NY 10042.

Received for publication 13 May 1994 and in revised form 1 November 1994.

J. Clin. Invest.

(C) The American Society for Clinical Investigation, Inc.

0021-9738/95/03/1071/07 \$2.00

Volume 95, March 1995, 1071-1077 destruction occurs within a few years after disease onset $(5,6)$. In recent years the knowledge of the basic structure of cartilage and bone has grown rapidly (7-10). Consequently, the possibilities of studying turnover in these tissues at the molecular level have increased. One approach is to quantify by immunoassay, tissue-specific matrix molecules released into synovial fluid and blood as a means of studying the turnover of matrix components in vivo (11-13). Such studies may help reveal basic mechanisms involved in matrix destruction. They may also lead to the development of clinically useful tools for disease monitoring. A problem, when interpreting results of measurements of matrix macomolecules or fragments thereof in body fluids, is that it is not apparent whether the released material represents newly synthesized components or degradation products of "resident" molecules. Since degradation is ordinarily coupled to an attempt at repair the release of matrix molecules should reflect both aspects of matrix turnover. Some analytes may preferentially reflect degradation while others may predominantly indicate repair. By assaying several molecules in the same sample of body fluid it should become possible to investigate matrix synthesis and degradation in different tissues.

In a previous study of early RA we showed that serum concentrations of a cartilage oligomeric matrix protein (COMP $)^{1}$ are initially elevated in those patients who later develop extensive joint destruction (14). This suggested that disease pathogenesis is characterized by abnormal turnover of this protein in these patients. We have now extended this study to studies of the cartilage proteoglycan aggrecan and type II collagen. We have also compared cartilage metabolism to that of bone by measuring the release of bone sialoprotein (BSP).

BSP is a bone-specific protein, produced by the osteoblast, with a molecular mass of $70-80 \mathrm{kD}$. It has a protein backbone of 33,600 $M_{\mathrm{r}}$ as determined by sequence analysis (8). The protein stimulates hydroxyapatite formation in vitro (15). It binds tightly to hydroxyapatite and contains an RGD integrin binding sequence. It thus might serve as a cell adhesion molecule allowing cells to attach to the extracellular matrix (8). Its synthesis is inhibited by 1,25-dihydroxyvitamine D3 but is stimulated by dexamethasone added to cultured osteoblastic cells or to cultured calvaria explants (8). BSP is particularly enriched in the cartilage-bone interphase (16). Synovial fluid levels of the protein are higher in RA patients with advanced joint destruction than in patients with well preserved joints (17).

1. Abbreviations used in this paper: COMP, cartilage oligomeric matrix protein; CPII, type II procollagen C-propeptide; 846 , the chondroitin sulfate epitope 846 in aggrecan; BSP, bone sialoprotein; CRP, C-reactive protein; ESR, erythrocyte sedimentation rate; HA, hyaluronan; KS, keratan sulfate; NSAID, non-steroidal antiinflammatory drug. 
Table I. Characteristics of the Patients

\begin{tabular}{|c|c|c|c|c|c|}
\hline \multirow[b]{2}{*}{ No of patients (female/male) } & \multicolumn{2}{|c|}{$\begin{array}{l}\text { Rapid erosive } \\
\text { group }\end{array}$} & \multicolumn{2}{|c|}{$\begin{array}{l}\text { Slow erosive } \\
\text { group }\end{array}$} & \multirow{2}{*}{$\frac{\text { Difference }}{-}$} \\
\hline & 9 & $(5 / 4)$ & 9 & $(5 / 4)$ & \\
\hline Age at disease onset (years) & 57 & $(25-65)$ & 59 & $(24-69)$ & NS \\
\hline \multicolumn{6}{|l|}{$\begin{array}{l}\text { First serum sample analyzed } \\
\text { (years after disease }\end{array}$} \\
\hline onset) & & $(0.2-2.1)$ & & $(0.2-1.8)$ & NS \\
\hline \multicolumn{6}{|l|}{ Radiographic index (Larsen) } \\
\hline at study entry & 7 & $(0-45)$ & 2 & $(0-16)$ & NS \\
\hline $1 \mathrm{yr}$ later & 26 & $(3-70)$ & 4 & $(0-16)$ & $P<0.002$ \\
\hline 2 yr later & 46 & $(24-90)$ & 4 & $(0-17)$ & $P<0.001$ \\
\hline \multicolumn{6}{|l|}{ Positive Waaler-Rose titer } \\
\hline$(>1 / 64)$ & & 5 & & 6 & NS \\
\hline
\end{tabular}

Except for number of patients and number of patients with positive Waaler-Rose test the figures denote median (range). For explanations, see text. $N S$, not significant.

COMP is a cartilage specific protein with the highest concentrations being found in articular cartilage (18). Oligomeric COMP has a molecular mass of $524 \mathrm{kD}$, as determined by sedimentation equilibrium ultracentrifugation (18). On SDSPAGE the reduced protein has an apparent molecular mass of $100 \mathrm{kD}$, suggesting that the protein is composed of five subunits. This structure was confirmed by rotary shadowing where the protein appeared as a bouquet-like, five armed structure (19). Cloning and sequence analysis subsequently showed that the COMP subunit corresponds to an $83-\mathrm{kD}$ polypeptide which has sequence homology with the thrombospondins, but is a unique gene product (20). Studies of circulating levels of COMP in relation to therapy suggest that this released COMP preferentially reflects matrix repair, but this hypothesis needs to be verified (T Saxne \& D Heinegård, unpublished observation).

The C-propeptide of type II collagen (CPII) is released by the activity of a C-proteinase, as procollagen is incorporated into the forming fibril (9). The rate of synthesis of type II collagen is directly proportional to the content of CPII in cartilage with a $t 1 / 2$ of $15-20 \mathrm{~h}$ (F. Nelson and A. R. Poole, manuscript in preparation). The propeptide is released from cartilage and enters the circulation where it can be detected by a specific immunoassay (21). Its presence in body fluids is therefore an indicator of cartilage collagen synthesis.

The chondroitin sulfate epitope of aggrecan recognized by the monoclonal antibody 846 is present in hardly detectable amounts in normal adult cartilages. Its content is greatest in fetal and neonatal cartilages (22). The epitope is a putative biosynthetic marker, the epitope being present on the largest molecules, which show $100 \%$ aggregability with hyaluronan. Moreover, the epitope is increased in content in osteoarthritic cartilage (23). Furthermore, preliminary in vitro studies indicate that the level of the epitope in cartilage is directly correlated with aggrecan biosynthesis (H. Jugessur and A. R. Poole, unpublished observations). Recent studies of patients with chronic RA have revealed that serum levels are frequently elevated but it shows the highest concentrations in synovial fluids of diseased joints (24). The available evidence to date thus suggest that fragments of aggrecan bearing the 846 epitope reflect the degradation of recently/newly synthesized aggrecan molecules.

In the present study we describe that rapid erosive joint disease is characterized by differences in the presence of these cartilage molecules in serum. Moreover, these changes may be of value in understanding the pathogenesis of joint disease. Furthermore, measurement of COMP and epitope 846 may assist in identifying patients at risk for rapid joint destruction.

\section{Methods}

\section{Patients and controls}

The 18 patients, who all fulfilled the established American Rheumatism Association Criteria for RA, have been previously described (14, 25 ). They were selected from a cohort of 150 patients with RA of recent onset monitored at the Department of Rheumatology in Lund (26). Nine patients were identified, who within 0.5-4 yr after disease onset developed significant erosive disease of the hip joints (Table I). All 9 patients required unilateral or bilateral hip arthroplasty after a median disease duration of $2.8 \mathrm{yr}$ (range 1.2-6 yr). Disease onset was defined as the time of onset of joint symptoms according to history at the initial visit to the department. These patients also developed erosive changes in their hands and feet. Another group of 9 RA patients, but without rapidly progressive disease leading to clinical hip involvement matched for age, gender, and disease duration was chosen from the group of 150 patients for comparison (Table I). The patients were selected based on their clinical features before any analysis of tissuemarkers was performed. The groups are referred to as rapid erosive and slow erosive, respectively.

All patients in the rapid erosive group received non-steroidal antiinflammatory drugs (NSAIDs). They were given a median of 11 intraarticular glucocorticoid injections during the study period, but no injection was given before the first serum sampling. Six patients were treated with slow acting antirheumatic drugs (chloroquine, sodium aurothiomalate, Dpenicillamine or azathioprine). In the slow erosive group, 7 patients were given NSAIDs, 2 paracetamol, and 2 were treated with D-penicillamine. These patients received a median of three intraarticular glucocorticoid injections during the study period. No patient received systemic corticosteroid treatment during the study period. Cartilage and bone molecular markers were measured in 3-5 serum samples from each patient during a median period of 2.7 years (range 1.6-4.2 yr) starting with the sample obtained at the patient's first visit to the department. This sample was drawn after a median of $0.9 \mathrm{yr}$ (range $0.2-2.1 \mathrm{yr}$ ) from disease onset. The control group comprised 18 healthy blood donors matched for age and gender of the patients. It included 10 females and 8 males with a median age of $56 \mathrm{yr}$, range $25-70 \mathrm{yr}$. Blood samples were collected into tubes without additives. The blood was allowed to clot for $2 \mathrm{~h}$ at room temperature and was then centrifuged and stored at $-80^{\circ} \mathrm{C}$.

\section{Radiographic examination}

Hands, wrists, and feet of the 18 RA patients were examined radiographically on study entry and 1 and 2 years later. The radiographs were graded by the same radiologist without knowledge of clinical data using the Larsen method modified according to Pettersson $(27,28)$. This method is based on comparisons with standard radiographs, where 0 denotes a normal appearing joint and 5 the one with most advanced changes. A theoretical range of values for these joints is $0-200$. The scores for the patient groups are shown in Table I. The radiographs of the hips of the patients in the aggressive group all showed advanced damage prior to surgery (Larsen grade 5). Radiographs of the hips of the patients in the slow erosive group were not available.

\section{Immunoassays}

COMP. The serum concentrations of COMP in the patient groups were those previously reported (14). Serum concentrations of COMP in the blood donors were determined using the same enzyme-linked inhibition immunosorbent assay (ELISA) $(14,29)$. Polyclonal antibodies raised in a rabbit against the bovine protein were used. Purified human COMP was used for coating the microtiter plates and standards of human COMP were included in each plate. In each plate, reference samples from serum 
pools were also included. The intra-assay variation is $<5 \%$ and the inter-assay variation is $<8 \%$.

CPII. A solution phase inhibition RIA was used employing bovine CPII isolated from fetal cartilage as described previously (21). It was radiolabeled with ${ }^{125} \mathrm{I}-\mathrm{NaI}$ (DuPont NEN, Boston, MA) using chloramine-T (21). A rabbit antiserum (R160) to bovine CPII prepared as described (21) was used as the first antibody: a pig anti-rabbit IgG serum prepared in the Joint Diseases Laboratory was used as the second antibody. Patient serum ( $75 \mu \mathrm{l})$ was mixed with $25 \mu \mathrm{l}$ extraction buffer (1.0\% CHAPS [Calbiochem Corp., La Jolla, CA], $2.0 \mathrm{M} \mathrm{NaCl}, 0.4 \mathrm{M}$ EDTA and $0.4 \mathrm{M}$ potassium acetate, $\mathrm{pH} 7.4$ ). To this were added 50 $\mu$ l of rabbit antiserum to CPII previously diluted with RIA buffer. The RIA buffer contained $0.15 \mathrm{M} \mathrm{Na}_{2} \mathrm{HPO}_{4} / \mathrm{KH}_{2} \mathrm{PO}_{4}, \mathrm{pH} 8.1$, with $0.25 \%$ bovine serum albumin, $0.5 \%$ sodium deoxycholate, $0.25 \%$ Nonidet $\mathrm{P}$ 40 (British Drug Houses, Montreal), and $0.05 \%$ sodium azide. The antiserum was diluted in RIA buffer to bind $40-50 \%$ of the total radiolabeled CPII. After mixing, the solution was left at room temperature for 18 h. $50 \mu{ }^{125}$ I-CPII ( 10,000 cpm) in RIA buffer were added. After overnight incubation at room temperature $25 \mu \mathrm{l}$ of non-immune rabbit serum (diluted 1/16 with RIA buffer) followed by $50 \mu \mathrm{l}$ of pig antirabbit IgG serum (previously precipitated with $50 \%$ ammonium sulfate to partially purify immunoglobulins but not to concentrate them). After incubation for $2 \mathrm{~h}$ at room temperature, $2 \mathrm{ml}$ RIA buffer were added before centrifugation at $1,800 \mathrm{~g}$ for $20 \mathrm{~min}$. Supernatants were aspirated and pellets were counted in a $\gamma$ counter. Polypropylene tubes $(12 \times 75$ $\mathrm{mm}$; Fisher Scientific, Montreal ) were used throughout, since CPII binds to glass. Standards ( $100 \mu \mathrm{l})$ were prepared using purified bovine CPII in one quarter strength extraction buffer.

A typical standard inhibition curve is shown in Fig. $1 a$. The interassay percentage coefficient of variation for serum samples was $9.3 \pm 9.3($ mean $\pm \mathrm{SD}, n=35)$ whereas the intraassay variation was $6.3 \pm 5.2(n=31)$. To investigate the recovery of CPII from serum, bovine CPII in the range $75-475 \mu \mathrm{g}$ was added to serum and assayed. Percentage recovery was $96.5 \pm 3.6$ (mean $\pm \mathrm{SD}, n=6$ ). Assay of varying volumes of serum permitted a comparison of the inhibition curves with the inhibition produced by a standard bovine preparation. The results (Fig. 1, $b$ and $c$ ) are for two separate sera. They showed good parallelity of inhibition curves.

846 epitope. Full details of this RIA used to analyze serum samples have recently been described (24).

$B S P$. Concentrations were determined by inhibition ELISA (17). Microtiter plates were coated with purified human BSP and an antiserum raised in a rabbit against human BSP was used as first antibody. A standard curve of dilutions of human BSP was included in each plate as well as reference samples from serum pools. The inter- and intraassay variations of the method are $<10 \%$.

\section{Analysis of erythrocyte sedimentation rate, $C$-reactive protein and hyaluronan}

Erythrocyte sedimentation rate (ESR) was determined according to Westergren and C-reactive protein (CRP) using immunoassay (30). Hyaluronan (HA) was analyzed using a radiometric assay (Pharmacia HA test; Pharmacia Diagnostica, Uppsala, Sweden) (31).

\section{Statistical calculations}

Differences between groups were calculated using Mann-Whitney's test for unpaired variables. Correlations were calculated using Spearman's correlation coefficient. $P$ values $<0.05$ were considered significant. Calculations were performed on the results of the measurements in the first sample obtained from each patient.

\section{Results}

COMP. The serum concentrations of COMP are shown in Fig. 2. Initially the concentrations were elevated in the group with rapid erosive disease, but subsequently decreased, probably a consequence of tissue loss. In 6/9 cases the concentrations de-
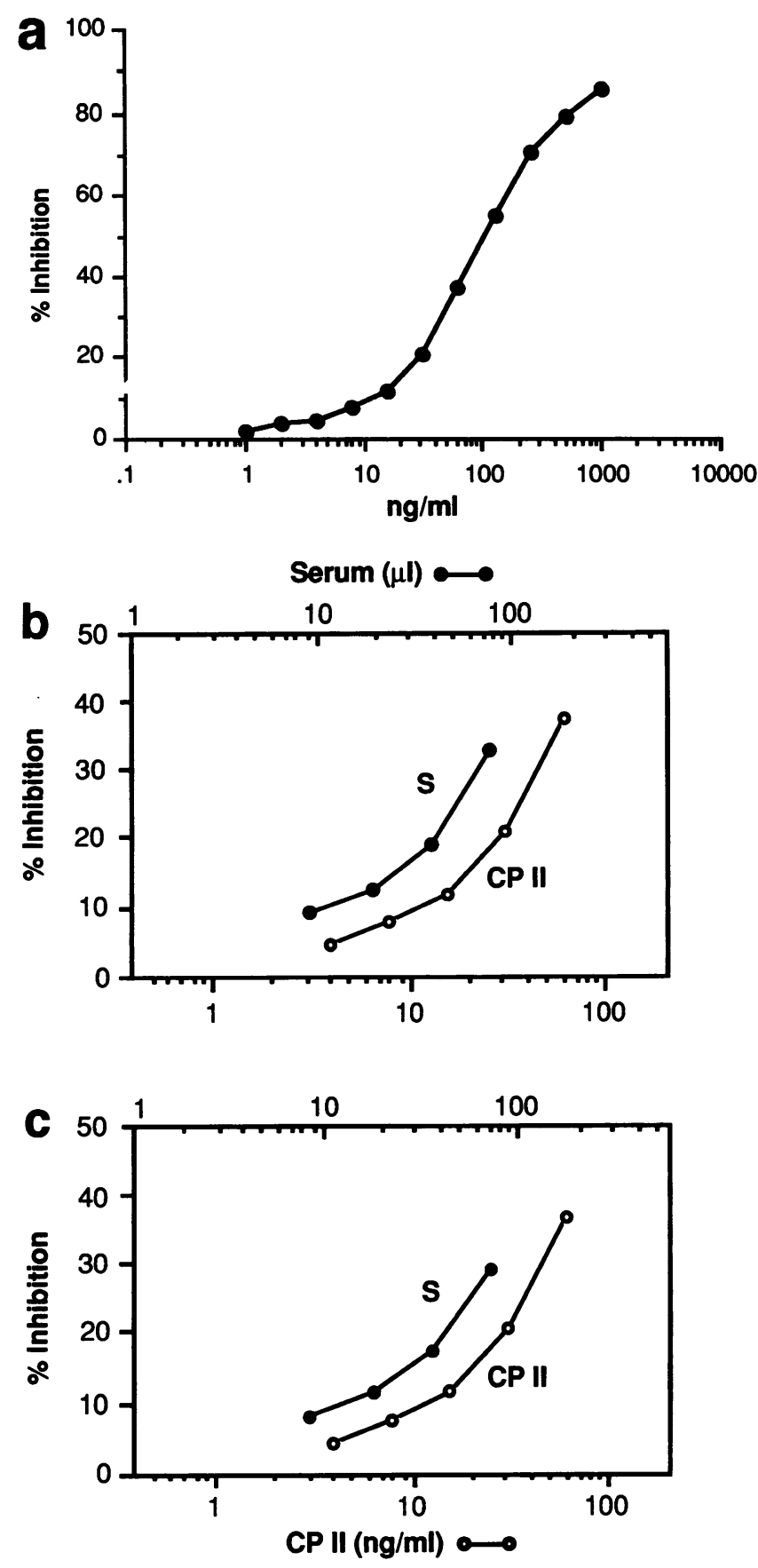

Figure 1. Radioimmunoassay of CPII in serum. Standard curves for purified bovine CPII are shown in full in $a$ and in part in $b$ and $c$. Inhibition produced by two different human sera are shown in $b$ and $c$. Parallelity of the standard and serum curves is apparent.

creased before surgery (14). The concentrations of the first samples assayed in both disease groups were significantly higher than those in the sera from the matched controls (Table II). First samples in the rapid erosive group showed significantly higher COMP concentrations than first samples in the slow erosive group (Table III).

CPII. The serum concentrations of CPII are shown in Fig. 3. The concentrations in both patient groups were increased compared to the concentrations in the controls (Table II). No significant difference between the patient groups were found 

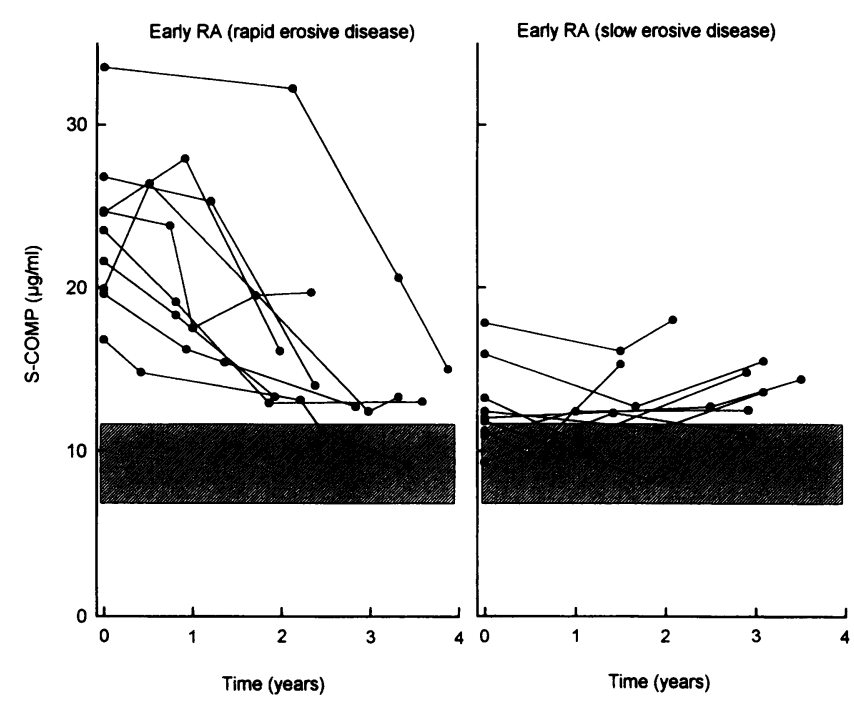

Figure 2. Serum concentrations of COMP in patients with rapid erosive or slow erosive RA. The first sample was obtained at the patient's first visit at the department. The shaded area denotes the range for serum concentrations of COMP in 18 age and sex-matched blood donors. For further explanation, see text.

for CPII levels in the first sample (Table III). However, three patients in the group with rapid erosive disease had considerably more elevated levels. These three patients also had the highest initial COMP levels. The levels of CPII did not change over time.

846 epitope. The concentrations of the 846 epitope are shown in Fig. 4. In contrast to the findings for COMP and CPII, levels were only elevated over the controls in those with slow erosive disease (Table II). Interestingly, the serum levels in the group with rapid erosive disease were often in the lower end of the normal range or even below the range of normal controls, although this did not reach statistical significance for the first patient samples. There were significant differences between the two disease groups for first samples (Table III). The serum levels showed no or minimal change with time.

$B S P$. The serum concentrations of BSP are shown in Fig.

Table II. Serum Concentrations of COMP, CPII, the 846 Chondroitin Sulfate Epitope and BSP in Samples Obtained from 18 Blood Donors

\begin{tabular}{lccc}
\hline & & \multicolumn{2}{c}{ Difference $(P$ value $)$} \\
\cline { 3 - 4 } & Controls & $\begin{array}{c}\text { vs. rapid } \\
\text { erosive group }\end{array}$ & $\begin{array}{c}\text { vs. slow } \\
\text { erosive group }\end{array}$ \\
\hline COMP $(\mu \mathrm{g} / \mathrm{ml})$ & $9.6(6.9-11.9)$ & $<0.0001$ & $<0.01$ \\
CPII $(\mathrm{ng} / \mathrm{ml})$ & $12.5(8.3-25.1)$ & $<0.0001$ & $<0.001$ \\
$846-$ epitope $(\mathrm{ng} / \mathrm{ml})$ & $94.0(58.0-135.0)$ & $\mathrm{ns}$ & $<0.0001$ \\
BSP $(\mathrm{ng} / \mathrm{ml})$ & $78.3(49.8-96.2)$ & $<0.0001$ & $<0.001$ \\
& & & \\
\hline
\end{tabular}

Figures denote median (range). The $P$ values denote the levels of significance for the difference between concentrations in controls and in RA patients with rapid or slow erosive disease, respectively, using Mann-Whitney's test for unpaired variables. ns, nonsignificant.
Table III. Serum Concentrations of COMP, CPII, and 846 Chondroitin Sulfate Epitope, BSP, ESR, CRP, and HA in the First Sample Obtained from Each Patient in the Rapid Erosive and Slow Erosive RA Patient Groups, Respectively

\begin{tabular}{lccc}
\hline & Rapid erosive group & Slow erosive group & $\begin{array}{c}\text { Difference } \\
(P \text { value })\end{array}$ \\
\hline COMP $(\mu \mathrm{g} / \mathrm{ml})$ & $23.5(16.8-33.5)$ & $12.0(9.3-17.8)$ & $<0.0001$ \\
CPII $(\mathrm{ng} / \mathrm{ml})$ & $31.7(22.7-52.7)$ & $26.7(19.1-32.7)$ & $\mathrm{ns}$ \\
$846-$ epitope $(\mathrm{ng} / \mathrm{ml})$ & $58.0(12.0-170.0)$ & $210(105.0-860.0)$ & $<0.0001$ \\
BSP $(\mathrm{ng} / \mathrm{ml})$ & $105.2(86.7-136.8)$ & $98.8(64.0-159.8)$ & $\mathrm{ns}$ \\
ESR $(\mathrm{mm} / \mathrm{lh})$ & $55(29-105)$ & $18(4-48)$ & $<0.001$ \\
CRP $(\mathrm{mg} / \mathrm{l})$ & $62(<5-249)$ & $5(<5-40)$ & $<0.001$ \\
HA $(\mathrm{ng} / \mathrm{ml})$ & $183.7(32.8-363.6)$ & $35.2(11.9-160.5)$ & $<0.01$ \\
& & & \\
\hline
\end{tabular}

Figures denote median (range). Each group consists of 9 patient samples. The $P$ values denote the levels of significance for the difference between the groups using Mann-Whitney's test for unpaired variables. $n s$, not significant.

5. The levels were higher in both the patient groups than in the controls for first samples (Table II). There was no difference between the patient groups for first samples (Table III). The levels did not show a consistent pattern of change over time.

$E S R, C R P$, and HA. Levels of ESR, CRP and HA, Fig. 6, were initially significantly elevated in the rapid erosive group compared to the slow erosive group (Table III).

Correlations between serum concentrations of the different molecules and markers of inflammation. The CPII and COMP levels showed significant positive correlations (first sample of both groups) (Table IV). In contrast, an inverse relation was found between levels of COMP and the 846 epitope, and between levels of CPII and the 846 epitope. BSP concentrations did not correlate with concentrations of any of the cartilage markers.

Further analysis of more traditional assessments of inflammation (ESR and CRP) and of HA (Table IV) revealed that both COMP and CPII showed direct correlations with ESR and

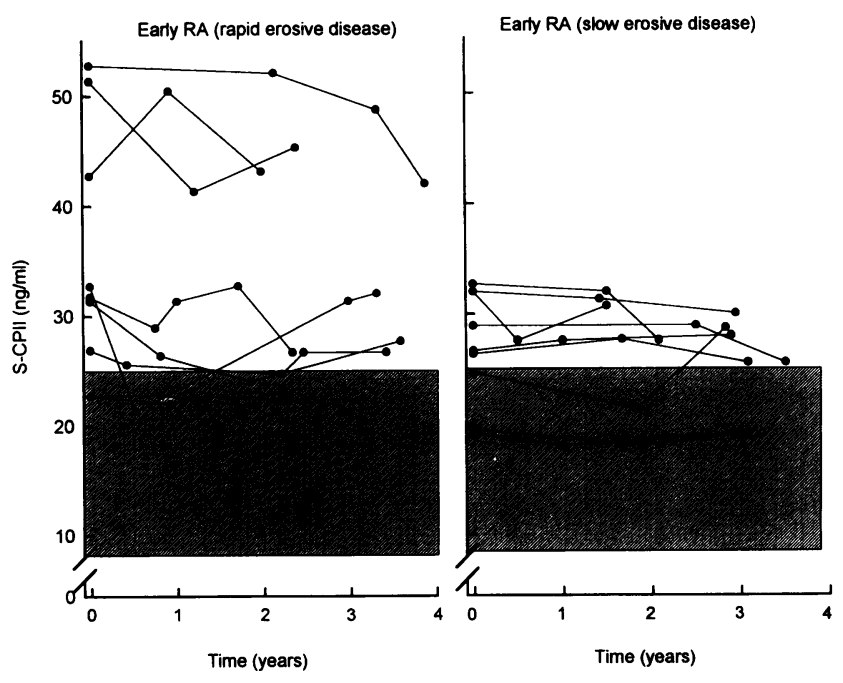

Figure 3. Serum concentrations of CPII in patients with rapid erosive or slow erosive RA. The first sample was obtained at the patient's first visit at the department. The shaded area denotes the range for serum concentrations of CPII in 18 age and sex-matched blood donors. For further explanation, see text. 


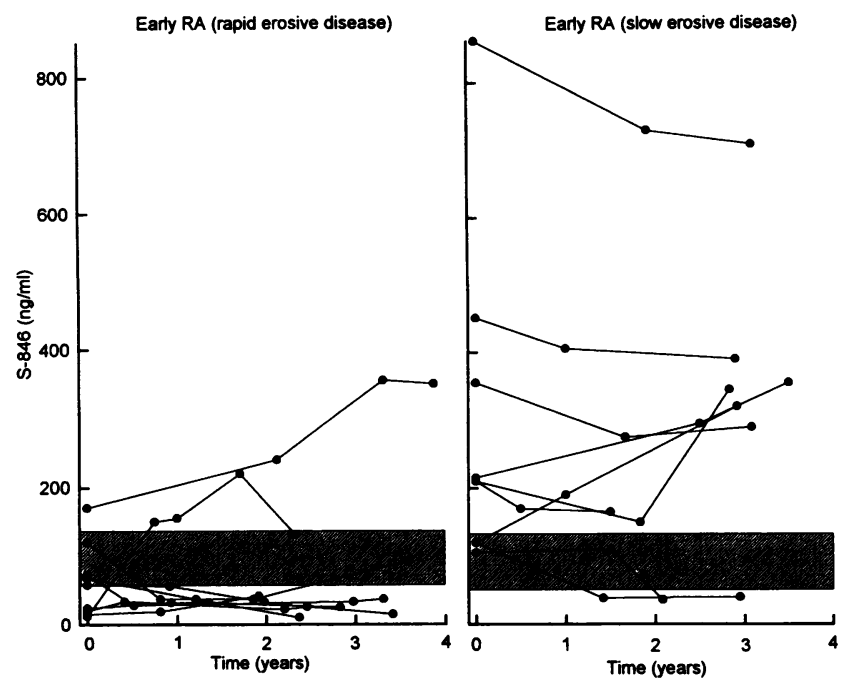

Figure 4. Serum concentrations of the chondroitin sulfate epitope 846 of aggrecan (846) in patients with rapid erosive or slow erosive RA. The first sample was obtained at the patient's first visit at the department. The shaded area denotes the range for serum concentrations of the 846 epitope in 18 age and sex-matched blood donors. For further explanation, see text.

HA and CPII with CRP and HA. In contrast, epitope 846 exhibited an inverse correlation with both CRP and ESR. No such correlations were seen for BSP.

\section{Discussion}

Current knowledge of the pathophysiology of tissue destruction and the macromolecular changes that occur in cartilage and bone in RA has been gained mainly from studies in vitro and of animal models $(32-34)$. The conclusions reached in such experiments do not necessarily apply to the human situation. Studies of tissue metabolism in vivo in humans are therefore needed to substantiate experimental data. Here we have used immunoassays for the quantification of cartilage and bone specific molecules which enter the circulation as part of tissue turnover in the hope that they may reflect changes in the metabolism of extracellular matrix in these tissues. We examined patients with early RA to elucidate whether those with rapid erosive joint disease exhibit differences in the circulating levels of these molecules compared to those that do not develop severe joint damage within the same time period. Albeit the number of patients analyzed was low, the results obtained should be representative, since patient selection was based on carefully defined clinical criteria with no knowledge of results from marker analyses.

There were some marked differences. In addition to the previously described elevation of COMP in rapid erosive disease, the most conspicuous finding was that whereas the concentrations of the chondroitin sulfate 846 epitope present in aggrecan were high in the sera of patients with slow erosive disease, as we described elsewhere (24), very low, often subnormal, levels were found in the group with rapid erosive disease. Since this epitope appears to be present on the largest aggrecan molecules, and likely those that are newly synthesized, it appears that the increased levels of the 846 epitope reflect increased aggrecan synthesis $(23,24)$. Thus, increased levels

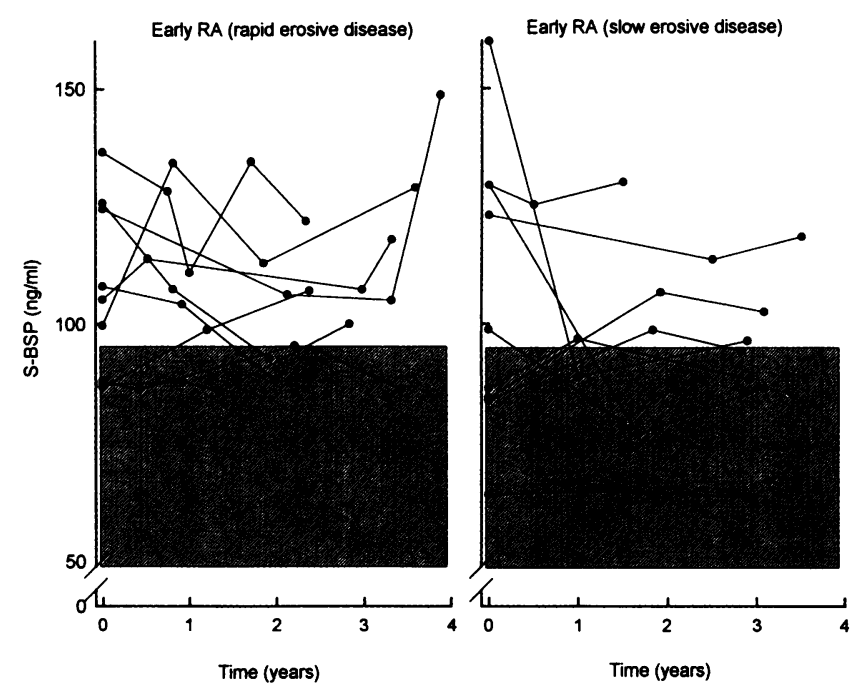

Figure 5. Serum concentrations of BSP in patients with rapid erosive or slow erosive RA. The first sample was obtained at the patient's first visit at the department. The shaded area denotes the range for serum concentrations of BSP in 18 age and sex-matched blood donors. For further explanation, see text.

of such marker analytes observed in serum may reflect an ability or at least an attempt to repair the damaged extracellular matrix. This is in accordance with higher levels in serum from those patients that do not develop such rapid joint destruction as seen in the rapid erosive group. Thus elevated serum levels of the 846 epitope in RA may be a favorable prognostic sign.

The very low, often subnormal, serum levels of the 846 epitope in patients with active joint destruction likewise may reflect inhibition of aggrecan synthesis. This could result from excessive production of cytokines as a component of the inflammatory erosive process. Both tumor necrosis factor $\alpha$ and interleukin-1 have been shown in vitro and in vivo to produce such effects (9). The inverse correlation of 846 epitope with CRP and ESR, both indexes of inflammation, supports an indirect relationship between cartilage repair and inflammation. However, as no information on epitope stability is available we cannot rule out that the low concentrations in the patients with more severe disease are due to greater destruction of the epitope.

Serum keratan sulfate (KS) has recently been found to correlate with the severity of articular damage in RA (35). Furthermore, serum KS levels correlate inversely with levels of tumor necrosis factor $\alpha$ (36). These findings resemble those presented here for the 846 epitope. However, the 846 epitope is located, in part at least, on distinct and different fragments to those bearing KS ( $\mathrm{H}$. Jugessur and A. R. Poole, unpublished observations). In the present patient groups we did not measure $\mathrm{KS}$ due to shortage of material, but we have measured core protein epitopes in the sera of these patients (14). Levels of these epitopes did not differ between the groups and did not correlate with levels of the 846 epitope $(r=0.141)$. Since we have previously found a strong correlation between serum $\mathrm{KS}$ and serum concentrations of core protein epitopes in arthritis (37), this clearly indicates that serum 846 epitope is a unique marker, reflecting other aspects of cartilage turnover than $\mathrm{KS}$ or core protein epitopes.

This is the first study in which we have examined the levels of CPII in patients. CPII is released from type II procollagen 


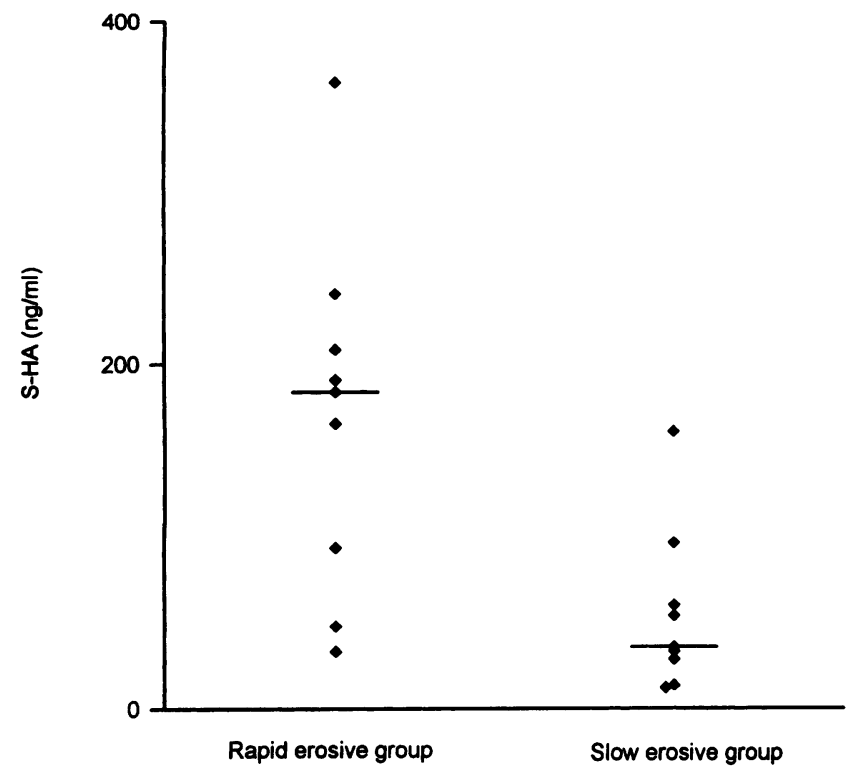

Figure 6. Serum concentrations of HA in patients with rapid erosive or slow erosive RA. Analyses were performed on the sample obtained at the patient's first visit at the department. The difference between the groups is significant $(P<0.01)$.

during synthesis and fibril assembly and tissue levels are directly related to the synthesis of this molecule (F. Nelson, E. Brooks, M. Ionescu, and A. R. Poole, manuscript in preparation ). In contrast to the 846 epitope, both disease groups showed significant elevations of CPII which were not significantly different from each other. This suggests that type II collagen synthesis is not as sensitive to the effects of inflammation as may be the synthesis of the cartilage proteoglycan aggrecan. Moreover, both CRP and ESR were directly correlated with CPII in contrast to the inverse correlation seen with the 846 epitope. In spite of the similarity in CPII levels in the two disease groups, changes in CPII levels in RA generally correlated very well with those of COMP.

Elevations of serum HA in RA most likely result from release of this molecule from the inflamed synovial membrane (35). The levels were highest in the rapid erosive group which corroborates previous findings of the most elevated HA levels in RA patients with rapid joint destruction (36). Furthermore, the serum levels of HA correlated with levels of the cartilage markers in a similar fashion as ESR and CRP. This supports a connection between joint and systemic inflammation and disturbance of cartilage matrix turnover in arthritis (37).

These observations suggest therefore that the synthesis and release of aggrecan may be differently regulated to that of type II collagen and COMP. This could reflect different effects of cytokines. Whereas TGF $\beta$ can stimulate COMP synthesis in adult human chondrocytes (A. D. Recklies, Joint Diseases Laboratory, Shriners Hospital, Montreal, unpublished results), there is no evidence to indicate that this can occur in these tissues at the level of aggrecan and collagen II. The differential effect on collagen and aggrecan turnover is surprising and may reflect differences in the relative sensitivity of chondrocyte synthesis of these molecules to stimulation and/or impairment of synthesis by cytokines.

Clearly, elevations of COMP measured alone early after
Table IV. Correlations between Serum Concentrations of COMP, the 846 Chondroitin Sulfate Epitope, CPII, BSP, ESR, CRP, and $H A$ in the First Sample of Both Groups of RA Patients

\begin{tabular}{lccccrr}
\hline & HA & CRP & ESR & BSP & CPII & $\begin{array}{c}\text { 846- } \\
\text { epitope }\end{array}$ \\
\hline COMP & $0.681^{\ddagger}$ & 0.428 & $0.529^{*}$ & 0.330 & $0.622^{\ddagger}$ & $-0.538^{*}$ \\
846-epitope & -0.377 & $-0.556^{*}$ & $-0.669^{\ddagger}$ & 0.010 & $-0.591^{\ddagger}$ & \\
CPII & $0.420^{*}$ & $0.529^{*}$ & $0.587^{\ddagger}$ & 0.231 & & \\
BSP & 0.100 & -0.037 & 0.114 & & & \\
ESR & $0.616^{\ddagger}$ & $0.864^{\S}$ & & & & \\
CRP & $0.548^{*}$ & & & & & \\
& & & & & &
\end{tabular}

$n=18$. The figures denote the Spearman correlation $\mathrm{r}$ values. ${ }^{*} P<0.05 ; \quad{ }^{\ddagger} P$ $<0.01 ;{ }^{8} P<0.001$

disease onset is the most valuable indicator of patients with an unfavourable prognosis in this study. Unlike the other cartilage molecules, COMP levels in the rapid erosive group tended to show a progressive decrease with time. The reasons for this are, however, at present unclear. It is unlikely that the surgical procedure influenced the serum concentrations significantly, since in most patients the decrease occurred prior to surgery. Only one patient in the rapid erosive group had slightly increased levels of the 846 epitope in all samples. Interestingly, this patient also had the highest COMP levels. Her CPII and BSP levels were also among the highest in the group. We were, however, not able to detect any signs, symptoms or other characteristics distinguishing this patient from the others in the group.

The serum concentrations of bone derived BSP were increased in both groups compared to levels in the controls, which is in line with previous observations in RA patients $(17 ; \mathrm{T}$. Saxne and $\mathrm{D}$. Heinegård unpublished). This is probably due to the generalized involvement of bone in RA with release of BSP from all bone including the vertebrae. Whether this involvement precedes or reflects the osteopenia commonly seen in this disease remains to be established. That the BSP concentrations did not differ between the patient groups, suggests that the influence of joint inflammation on the metabolism of the juxtaarticular bone of large joints of the rapidly destructive group may be too small to show against the background of disturbed generalized bone turnover and that these changes reflect more generalized alterations in bone metabolism, which we observed regardless of the progression of joint disease. Corticosteroid treatment is known to influence the bone metabolism. Therefore it is noteworthy that the increased BSP levels in both groups were present before any intraarticular corticosteroid injections had been given. Furthermore, there was no correlation between the incidence of corticosteroid injections and changes in serum BSP levels during the study. Notably, statistical comparisons for all markers were made on results of samples obtained before any intraarticular corticosteroid injections had been given. Thus, the differences reported for the cartilage markers appear not to be biased by such treatment.

This study represents a first attempt to use combined measurements of several tissue-specific skeletal components in sera of clinically well-defined patient groups with RA to investigate disease activity. This approach opens new avenues to the understanding of the complexity of the skeletal metabolism in arthritis and raises new questions. By combining the clinical characteristics and the marker data it may be possible to increase the knowledge of the basic pathophysiology of joint disease and to 
use this information in clinical settings, such as for prognostic purposes and in therapeutic studies.

These observations draw attention to the fact that the measurement of cartilage derived macromolecules may be of prognostic value in determining disease progression, specifically at the level of erosive joint destruction.

\section{Acknowledgments}

The HA test was a gift from Pharmacia Diagnostica, Uppsala, Sweden. Skillful technical assistance by Mrs. Mette Lindell is appreciated.

Grants were obtained from The Medical Faculty of Lund, The Swedish Medical Research Council, Ax:son Johnsons Stiftelse, CIBA-GEIGY Corp., Österlunds, Kocks and Crafoords Stiftelser, Konung Gustaf V:s 80-årsfond, Procordias Forskningsstiftelse, Lasarettets i Lund fonder, Riksförbundet mot Reumatism (to B. Månsson, T. Saxne and D. Heinegård), Shriners of North America, Pharmacia Diagnostics and the Medical Research Council of Canada (to A. R. Poole) and National Institutes of Health (to L. C. Rosenberg). Dr. Dennis Carey was the recipient of a Fogarty Fellowship from the National Institutes of Health during his fellowship in Montreal.

\section{References}

1. Harris, E. D., Jr. 1993. Etiology and pathogenesis of rheumatoid arthritis. In Textbook of Rheumatology. 4th edition. W. N. Kelley, E. D. Harris, Jr., S. Ruddy, and C. B. Sledge, editors. W. B. Saunders Company, Philadelphia, PA. 833-873.

2. Panayi, G. S. 1992. The immunopathogenesis of rheumatoid arthritis. Rheumatology Review. 1:63-74.

3. Harris, E. D., Jr. 1990. Rheumatoid arthritis. Pathophysiology and implications for therapy. N. Engl. J. Med. 322:1277-1289.

4. Krane, S. M. 1989. Mechanisms of tissue destruction in rheumatoid arthritis In Arthritis and Allied Conditions. 11th edition. D. J. McCarty, editor. Lea \& Febiger, Philadelphia, PA. 698-714.

5. Van der Heijde, D., P. van Riel, M. van Rijswijk, and L. van de Putte. 1988. Influence of prognostic features on the final outcome in rheumatoid arthritis: a review of the literature. Sem. Arthritis. Rheum. 17:284-292.

6. Van der Heijde, D., P. van Riel, M. van Leeuween, M. van't Hof, M. van Rijswijk, and L. van de Putte. 1992: Prognostic factors for radiographic damage and physical disability in early rheumatoid arthritis. A prospective follow-up study of 147 patients. Br. J. Rheumatol. 31:519-528.

7. Heinegård, D., and $\AA$. Oldberg. 1989. Structure and biology of cartilage and bone matrix noncollagenous macromolecules. FASEB (Fed. Am. Soc. Exp. Biol.) J 3:2042-2051.

8. Heinegård, D., and A. Oldberg. 1993. Glycosylated matrix proteins. In Connective Tissue and Its Heritable Disorders. P. M. Royce and B. Steinmann, editors. Wiley-Liss, Inc., New York. 189-209.

9. Poole, A. R. 1993. Cartilage in health and disease. In Arthritis and Allied Conditions, 12th edition. D. J. McCarthy and W. J. Koopman, editors. Lea \& Febiger, Philadelphia, PA 279-333.

10. von der Mark, K., and S. Goodman. 1993. Adhesive glycoproteins. In Connective Tissue and Its Heritable Disorders. P. M. Royce and B. Steinmann, editors. Wiley-Liss Inc., New York. 211-236.

11. Heinegård, D., and T. Saxne. 1991. Molecular markers of processess in cartilage in joint disease. Br. J. Rheumatol. 30(suppl. 1):21-24.

12. Thonar, E. J. M. A., M. Shinmei, and L. S. Lohmander. 1993. Body fluid markers of cartilage changes in osteoarthritis. Rheum. Dis. Clin. North Am. 19:635-657.

13. Poole, A. R. 1994. Immunochemical markers of joint inflammation, skeletal damage and repair: where are we now? Ann. Rheum. Dis. 53:3-5.

14. Forslind, K., K. Eberhardt, A. Jonsson, and T. Saxne. 1992. Increased serum concentrations of cartilage oligomeric matrix protein. A prognostic marker in early theumatoid arthritis. Br. J. Rheumatol. 31:593-598.

15. Hunter, G. K., and H. A. Goldberg. 1993. Nucleation of hydroxyapatite by bone sialoprotein. Proc. Natl. Acad. Sci. USA. 90:8562-8565.

16. Ibrisevic, E., S. Mengarelli-Widholm, F. P. Reinholt, D. Heinegård, and O. Svensson. 1993. Distribution of bone sialoprotein at the articular osteocartilaginous interface. Transactions of the 39th Annual Meeting, Orthopaedic Research Society. 216 (Abstr.)

17. Saxne, T., L. Zunino, and D. Heinegård. 1995. Increased release of bone sialoprotein into synovial fluid reflects tissue destruction in rheumatoid arthritis. Arthritis. Rheum. In press.
18. Hedbom, E., P. Antonsson, A. Hjerpe, D. Aeschlimann, M. Paulsson, E. Rosa-Pimentel, Y. Sommarin, M. Wendel, À. Oldberg, and D. Heinegård. 1992. Cartilage matrix proteins: an acidic oligomeric protein (COMP) detected only in cartilage. J. Biol. Chem. 267:6132-6136.

19. Mörgelin, M., D. Heinegård, J. Engel, and M. Paulsson. 1992. Electron microscopy of native COMP (cartilage oligomeric matrix protein) purified from the Swarm rat chondrosarcoma reveals a five-armed structure. J. Biol. Chem. 267:6137-6141.

20. Oldberg, Å., P. Antonsson, K. Lindblom, and D. Heinegård. 1992. COMP (cartilage oligomeric matrix protein) is structurally related to the thrombospondins. J. Biol. Chem. 267:22346-22350.

21. Hinek, A., and A. R. Poole. 1988. The influence of vitamin D metabolites on the calcification of cartilage matrix and the C-propeptide of type II collagen (chondrocalcin). J. Bone. Min. Res. 3:421-429.

22. Glant, T. T., K. Mikecz, P. J. Roughley, E. Buzas, and A. R. Poole 1986. Age-related changes in protein-related epitopes of human articular cartilage proteoglycans. Biochem. J. 236:71-75.

23. Rizkalla, G., A. Reiner, E. Bogoch, and A. R. Poole. 1992. Studies of the articular cartilage proteoglycan aggrecan in health and osteoarthritis. Evidence for molecular heterogeneity and extensive molecular changes in disease. J. Clin. Invest. 90:2268-2277.

24. Poole, A. R., M. Ionescu, A. Swan, and P. A. Dieppe. 1994. Changes in cartilage metabolism in arthritis are reflected by altered serum and synovial fluid levels of the cartilage proteoglycan aggrecan: implications for pathogenesis. $J$. Clin. Invest. 94:25-33.

25. Arnett, F. C., S. M. Edworthy, D. A. Bloch, D. J. McShane, J. F. Fries, N. S. Cooper, L. A. Healey, S. R. Kaplan, M. H. Liang, H. S. Luthra, T. A. Medsger, Jr., D. M. Mitchell, D. H. Neustadt, R. S. Pinals, J. G. Schaller, J. T. Sharp, R. L. Wilder, and G. G. Hunder. 1988. The American Rheumatism Association 1987 revised criteria for the classification of rheumatoid arthritis. Arthritis. Rheum. 31:315-324.

26. Eberhardt, K. B., L. C. Rydgren, H. Pettersson, and F. A. Wollheim. 1990. Early rheumatoid arthritis-onset, course and prognosis over two years. Rheumatol. Int. 10:135-142.

27. Larsen, A., K. Dale, and M. Eek. 1977. Radiographic evaluation of rheumatoid arthritis and related conditions by standard reference films. Acta. Radiol. Diagnosis. 18:481-491.

28. Wollheim, F. A., H. Pettersson, T. Saxne, and K. G. Sjöblom. 1988. Radiographic assessment in relation to clinical and biochemical variables in rheumatoid arthritis. Scand. J. Rheumatol. 17:445-453.

29. Saxne, T., and D. Heinegård. 1992. Cartilage oligomeric matrix protein: A novel marker of cartilage turnover detectable in synovial fluid and blood. $B r$. J. Rheumatol. 31:583-591.

30. Laurell, C. B. 1972. Electroimmunoassay. Scand. J. Clin. Lab. Invest. (Suppl) 29:21-37.

31. Brandt, R., E. Hedlöf, I. Åsman, A. Bucht, and A. Tengblad. 1987. A convenient radiometric assay for hyaluronan. Acta. Otolaryngol. (Stockholm) Suppl. 442:31-35.

32. Choi, H. O., L. H. Tang, T. L. Johnson, S. Pal, L. Rosenberg, A. Reiner, and A. R. Poole. 1983. Isolation and characterization of a 35,000 molecular weight subunit fetal cartilage matrix protein. J. Biol. Chem. 258:655-661.

33. Mankin, H. J., and L. Lipiello. 1971. The glycosaminoglycans of normal and arthritic cartilage. J. Clin. Invest. 50:1712-1719.

34. Thompson, R. C., and T. Oegema, Jr. 1979. Metabolic activity of articular cartilage in osteoarthritis. An in vitro study. J. Bone. Jt. Surg. 61 A:407-416.

35. Haraoui, B., E. J-M. A. Thonar, J. Martel-Pelletier, J-R. Goulet, J-P. Raynauld, M. Oullet, and J.-P. Pelletier. 1994. Serum keratan sulfate levels in rheumatoid arthritis: Inverse correlation with radiographic staging. J. Rheumatol. 21:813-817.

36. Manicourt, D-H., R. Triki, K. Fukuda, J-P. Devogelaer, C. Nagant de Deuxchaisnes, and E. J.-M. A. Thonar. 1993. Levels of circulating tumor necrosis factor $\alpha$ and interleukin-6 in patients with rheumatoid arthritis. Relationship to serum levels of hyaluronan and antigenic keratan sulfate. Arthritis Rheum. 36:490-499.

37. Saxne, T., J. Hayford, D. Heinegård, M. E. Lenz, E. Thonar, F. A. Wollheim, and L. Pachman. 1989. Serum levels of the proteoglycan core protein and keratan sulfate correlate in juvenile rheumatoid arthritis. Arthritis Rheum. 32 (suppl 4):S105.

38. Hedin, P. J., T. Weitoft, H. Hedin, A. Engström-Laurent, and T. Saxne. 1991. Serum concentrations of hyaluronan and proteoglycan in joint disease. Lack of association. J. Rheumatol. 18:1601-1605.

39. Paimela, L., A. Heiskanen, P. Kurki, T. Helve, and M. Leirisalo-Repo. 1991. Serum hyaluronate level as a predictor of radiologic progression in early rheumatoid arthritis. Arthritis. Rheum. 34:815-821.

40. Poole, A. R., J. Witter, N. Robets, F. Piccolo, R. Brandt, J. Paquin, and M. Baron. 1990. Inflammation and cartilage metabolism in rheumatoid arthritis. Studies of the blood markers hyaluronic acid, orosomucoid and keratan sulfate. Arthritis. Rheum. 33:790-799. 